\title{
The Determinants of Health Status: Evidence from Asian Developing Countries
}

\author{
SM Zahedul Islam Chowdhury* \\ Research Fellow, Bangladesh Institute of Development Studies (BIDS), Dhaka
}

*Corresponding author: SM Zahedul Islam Chowdhury, Research Fellow, Bangladesh Institute of Development Studies (BIDS), Dhaka

\section{ARTICLE INFO}

Received: 幽 December 18, 2019

Published: 幽January 06, 2020

Citation: SM Zahedul Islam Chowdhury, The Determinants of Health Status: Evidence from Asian Developing Countries. Biomed J Sci \& Tech Res 24(2)-2020. BJSTR. MS.ID.004018.

\begin{abstract}
The paper estimates a health production function for Asian developing countries based on the Grossman (1972) theoretical model that treats social, economic, and environmental factors as inputs of the production system. In estimating this function, socioeconomic and environmental factors such as income per capita, literacy rate, food availability, health expenditure, health services, urbanization rate, population, and carbon dioxide emission are specified as determinants of health status. The parameters of the function are estimated by one-way and two-way fixed and random effects model of panel data analyses. The results of the one-way fixed effect model suggest that an increase in GDP per capita, food availability and literacy rate, and decrease in carbon dioxide emissions are strongly associated with an improvement in life expectancy at birth. Overall, the results imply that a health policy may focus on the provision of health services and environmental aspects may do little to improve the current health status of the region.
\end{abstract}

Keywords: Health Status; Asian Developing Countries; Human Development; Literacy; Life Expectancy; Framework

\section{Introduction}

Health is now universally regarded as an important index of human development. Ill health is both the cause and effect of poverty, illiteracy and ignorance. Policies of human development not only raise the income of the people but also improve other components of their standard of living, such as life expectancy, health, literacy, knowledge and control over their destiny. While it is true that health is not everything, it is also true that without health, everything else is nothing. An analysis of health status is an important aspect of human resource development. Improvements in health do not only improve the productivity of the labor force, but they also help to improve the impact of other forms of human capital formation, e.g. education. In most developing countries health status is difficult to determine as the question arises as to what measures should be used as indicators of health status. However, the improvement in health status can be observed most obviously from increases in life expectancy which is a better measure for cross country comparison than age and disease-specific mortality or morbidity, which are more difficult to compare at the international level. The remaining sections of the paper are organized as follows. The next sections outline literature review and empirical framework derived from the Grossman (1972) theoretical model and then describes data and the econometric methods to be followed in the estimation process. The last two sections will present and interpret the results and draw some conclusions.

\section{Literature Review}

In most empirical studies, per capita income, adult literacy, nutritional status and the availability of health services are included as important determinants of health status and per capita income and adult literacy are significant determinants of life expectancy in less developed countries but nutritional status is not statistically significant [1-7]. The study by Grosse and Perry [8] tries to find the correlates of life expectancy during the 1950s and the 1970s. Their results also show that per capita income and literacy rates are the major determinants of health status. However, this study draws some important conclusions regarding the significance of general social indicators like sanitation, transport and communications. 
Socioeconomic factors have also long been considered as important determinants of health outcomes, which are now widely known as "social determinants of health" (SDH) [9] . Reviewing both experimental and observational studies, it is concluded that there is abundant evidence at both the microeconomic and macroeconomic levels showing that a variety of health indicators are positively associated with different dimensions of economic prosperity and the causal pathways linking health and economic outcomes run in both directions and health capital has a positive impact on aggregate economic output [10]. According to the analysis, about one-fourth of economic growth was attributable to health capital accumulation, and health condition equivalent to one additional year of life expectancy is correlated with higher economic growth of up to $4 \%$ per year.

\section{The Framework}

Grossman (1972)1 developed a theoretical health production function, which can be specified as:

$$
H=F(X)
$$

where $\mathrm{H}$ is a measure of individual health output and $\mathrm{X}$ is a vector of individual inputs to the health production function F. The elements of the vector include: nutrient intake, income, consumption of public goods, education, time devoted to health related procedures, initial individual endowments like genetic makeup, and community endowments such as the environment.

This theoretical model was designed for analysis of health production at micro level. The interest here is, however, to analyze the production system at macro level. To switch from micro to macro analysis, without losing the theoretical ground, the elements of the vector $\mathrm{X}$ were represented by per capita variables and regrouped into sub-sectoral vectors of economic, social, and environmental factors as:

$$
h=F(Y, S, V)
$$

Where $\mathrm{Y}$ is a vector of per capita economic variables, $\mathrm{S}$ is a vector of per capita social variables, and $V$ is a vector of per capita environmental factors. In its scalar form, Equation 2 can be rewritten as

$$
h=f\left(y_{1}, y_{2} \ldots . y_{n}, S_{1}, S_{2}, \ldots s m, v_{1}, v_{2}, \ldots v_{t}\right)
$$

where $\mathrm{h}$ is individual's health status proxied by life expectancy at birth, $\left(\mathrm{y}_{1}, \mathrm{y}_{2} \ldots . \mathrm{yn}=\mathrm{Y} ;\left(\mathrm{s}_{1}, \mathrm{~s}_{2}, \ldots \mathrm{sm}\right)=\mathrm{S} ;\left(\mathrm{v}_{1}, \mathrm{v}_{2}, \ldots \mathrm{v}_{\mathrm{t}}\right)=\mathrm{V}\right.$, and $\mathrm{n}, \mathrm{m}$, and I are number of variables in each sub-group, respectively.

Using calculus, (3) can be transformed to its explicit form and given as

$$
h=\Omega \Pi y i \alpha i \Pi s j \beta j \Pi y i \Upsilon k
$$

where $\alpha i, \beta j, \Upsilon k$ are elasticities.

From Equation 4, we observe that $\Omega$ estimates the initial health stock pointed out by Grossman (1972). It measures the health status that would have been observed had there were no health depreciation, or health improvement due to changes in socioeconomic and environmental factors used in the production

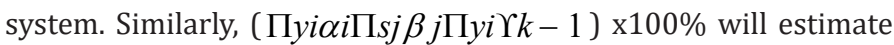
the percentage change in the health status due to socioeconomic and environmental factors. In this empirical analysis here, the variables representing economic factors are limited to include GDP per capita $\left(y_{1}\right)$, health expenditure per capita $\left(y_{2}\right)$ and food availability $\left(y_{3}\right)$; variables representing social factors are limited to education/ literacy rate) (s1), health service (physician per thousand people) $\left(\mathrm{s}_{2}\right)$ and population $\left(\mathrm{s}_{3}\right)$; and variables representing environmental factors include urbanization/ Urban Population ( $\%$ of Total) $\left(\mathrm{v}_{1}\right)$ and carbon dioxide emissions per capita $\left(\mathrm{v}_{2}\right)$. The population variable enters the equation to augment food availability data, as the data exist at aggregate index form. Taking the logarithm of (4) and rearranging it yields:

$$
\operatorname{Lnh}=\ln \Omega+\Sigma \alpha i\left(\ln y_{t}\right)+\Sigma \beta j\left(\ln _{S j}\right)+\Sigma \Upsilon k\left(\ln v_{k}\right)
$$

where $\mathrm{i}=1,2,3 ; \mathrm{j}=1,2,3$; and $\mathrm{k}=1,2$ and $\Omega$ is an estimate of the initial health stock of the region.

\section{Variables}

For the purpose of this study life expectancy at birth is used as health status indicators. GDP is per capita gross domestic product. The growth of GDP is expected to improve health status in a country. As incomes grow households can spend more money on looking after their health. Health expenditure per capita is expected to have a positive influence on health status. This variable has important implications for policy purposes as well. Improvements in food availability are expected to improve the nutritional status of a nation, and consequently the health status. However, the effect may be very strong at the initial changes in food availability and then may be slower after a certain level of nutrition has been achieved. Education (literacy) is expected to have a positive effect on health. However, it is difficult to say that its coefficient will reveal the net effect of changes in human capital as it may be correlated with the distribution of wealth. The availability of physicians indicates the availability of health services. If physician increases, it implies that the price of health services is rising, and the health status will deteriorate and vice versa. Population variable is introduced the in the function to correct the food availability index. Keeping all else constant, the larger population size, the lesser the food availability; hence, we expect a negative coefficient for the population variable.

Urbanization is the percentage of population living in urban areas. This variable may have a positive or negative effect. If an increase in urbanization means quick access to better health services, the effect is expected to be positive. However, if it results in inefficient health services or if it creates environmental problems it can lead to adverse effects on health. Carbon dioxide emissions per capita is another variable we considered as an environmental factor. Since the emissions cause air pollution that in turn causes health hazards, we expect negative coefficient for the variable. 


\section{Data and Method}

\section{Data}

Panel data for 25 Asian developing countries during the period of 1994-2013 are used. Data are taken from the World Development Indicators, $\mathrm{WB}$.

\section{Estimation Method}

For estimation of the parameters under consideration, a panel data analytic approach is employed. An econometric model is specified for Equation 5 in its general form. In order to provide an empirical exposition of the model, the specification is given as follows:

$$
h^{*}(g, t)=\delta(g)+\Gamma(t)+X *(g, t) \cdot \Phi+\Psi(g, t)
$$

where $h^{*}(g, t)$ is natural logarithm of life expectancy in country $\mathrm{g}$ at year $\mathrm{t}$, and $\mathrm{X}^{*}(\mathrm{~g}, \mathrm{t})$ is vector of explanatory variables $\left(\mathrm{y}_{1}, \mathrm{y}_{2}, \mathrm{y}_{3^{\prime}}\right.$, $\mathrm{s}_{1}, \mathrm{~s}_{2}, \mathrm{~s}_{3}, \mathrm{v}_{1}, \mathrm{v}_{2}$ ) for $\mathrm{g}=1,2, \ldots, \mathrm{m}$ (number of countries), $\mathrm{t}=1,2, \ldots, \mathrm{T}$ (number of years), $\Phi$ is vertical vector of parameters $(\alpha 1, \alpha 2, \alpha 3$, $\beta 1, \beta 2, \beta 3, \gamma 1, \gamma 2) ; \Psi(\mathrm{g}, \mathrm{t})$ is a classical stochastic disturbance term with $\mathrm{E}[\Psi(\mathrm{g}, \mathrm{t})]=0$ and $\operatorname{var}[\Psi(\mathrm{g}, \mathrm{t})]=\sigma \varepsilon 2 ; \delta(\mathrm{g})$ and $\Gamma(\mathrm{t})$ are group and time specific effects, respectively. Equation 6 is estimated by restricted OLS, Fixed Effects Model and Random Effects Model (both One-way and Two-Way).After estimating the parameters on the ground of these five assumptions, the superior specification is selected on the ground of suitable statistical test. In FEM, the intercept in the regression model is allowed to differ among individuals in recognition to the fact that each individual or cross-

Table 1: One-way error component regression model. sectional unit may have some special characteristics of its own. Meanwhile, REM assumed that the intercept of an individual unit is a random drawing from a much larger population with a constant mean value. If it is assumed that the error component $\beta$ and X's regressors are uncorrected, REM may be more suitable, whereas if $\beta$ and X's are correlated, FEM may be appropriate. Hausman test can be used to differentiate between fixed effect model (FEM) and random effect model (REM). The null hypothesis underlying the Hausman test is that the FEM and REM estimators do not differ significantly. If null hypothesis is rejected (at 1\% to $5 \%$ significant levels only), the FEM may be more appropriate to be used compared to the REM.

\section{Econometric Results}

Equation 6 is estimated using the data and method described above. The empirical results are given in Tables 1 and 2 . To choose from One-Way and Two-Way specifications, we use the F-test. The statistics tests the significance of any time specific effect that is not included in One-Way regression specification. We know that if simpler model (one way in this case) is correct if we get an F ratio near 1.0. If the ratio is much greater than 1.0, the more complicated model (two way) is correct. The test result given at the bottom of Table 2 suggests that a One-Way error component regression model is superior to Two-Way. Next, for the choice between random effects (GLS estimator) and fixed effect estimator, a Hausman test is performed. This implies that the preferable estimates of the parameters in Equation 6 can be given by one-way fixed effect model.

\begin{tabular}{|c|c|c|c|c|c|}
\hline Estimators & Parameters & Estimate of the Parameter & SE & t-ratio & p-value \\
\hline \multirow{9}{*}{ Restricted OLS } & $\alpha 1$ & 0.0001 & 0.0001 & 0.3500 & 0.7260 \\
\hline & $\alpha 2$ & 0.0077 & 0.0029 & 2.6200 & 0.0100 \\
\hline & $\alpha 3$ & 0.0195 & 0.0096 & 2.0400 & 0.0430 \\
\hline & $\beta 1$ & 0.1630 & 0.0135 & 12.0500 & 0.0000 \\
\hline & $\beta 2$ & 2.0839 & 0.2499 & 8.3400 & 0.0000 \\
\hline & $\beta 3$ & -0.0000 & 0.0000 & -6.3400 & 0.0000 \\
\hline & $\Upsilon 1$ & 0.0329 & 0.0223 & 1.4800 & 0.1420 \\
\hline & $\Upsilon 2$ & 0.0477 & 0.0929 & 0.5100 & 0.6080 \\
\hline & Constant & 52.3023 & 1.3922 & 37.5700 & 0.0000 \\
\hline Estimators & Parameters & Estimate of the Parameter & SE & t-ratio & p-value \\
\hline \multirow{9}{*}{ Fixed Effect Model } & $\alpha 1$ & 0.0002 & 0.0001 & 1.9800 & 0.0490 \\
\hline & $\alpha 2$ & -0.0077 & 0.0020 & -3.7600 & 0.0000 \\
\hline & $\alpha 3$ & 0.0361 & 0.0062 & 5.8000 & 0.0000 \\
\hline & $\beta 1$ & 0.1757 & 0.0391 & 4.4900 & 0.0000 \\
\hline & $\beta 2$ & 0.1863 & 0.4851 & 0.3800 & 0.7010 \\
\hline & $\beta 3$ & -0.0000 & 0.0000 & -1.8500 & 0.0670 \\
\hline & $\Upsilon 1$ & 0.2279 & 0.0382 & 5.9600 & 0.0000 \\
\hline & $\Upsilon 2$ & -0.1799 & 0.0945 & -1.9000 & 0.0590 \\
\hline & Constant & 42.2884 & 2.6862 & 15.7400 & 0.0000 \\
\hline Estimators & Parameters & Estimate of the Parameter & SE & t-ratio & p-value \\
\hline
\end{tabular}




\begin{tabular}{|c|c|c|c|c|c|}
\hline \multirow{9}{*}{ Random Effect Model } & $\alpha 1$ & 0.0002 & 0.0001 & 2.1400 & 0.0330 \\
\hline & $\alpha 2$ & -0.0088 & 0.0021 & -4.2700 & 0.0000 \\
\hline & $\alpha 3$ & 0.0373 & 0.0059 & 6.2800 & 0.0000 \\
\hline & $\beta 1$ & 0.1378 & 0.0274 & 5.0300 & 0.0000 \\
\hline & $\beta 2$ & 0.6159 & 0.4278 & 1.4400 & 0.1500 \\
\hline & $\beta 3$ & -0.0000 & 0.0000 & -1.1900 & 0.2350 \\
\hline & $\Upsilon 1$ & 0.1649 & 0.0298 & 5.5400 & 0.0000 \\
\hline & $\Upsilon 2$ & -0.1912 & 0.0933 & -2.0500 & 0.0400 \\
\hline & Constant & 46.8315 & 1.9269 & 24.3000 & 0.0000 \\
\hline Hausman Test & \multicolumn{5}{|c|}{$\operatorname{chi} 2(6)=31.19, \mathrm{p}=0.0000$} \\
\hline
\end{tabular}

Table 2: Two-way error component regression model.

\begin{tabular}{|c|c|c|c|c|c|}
\hline Estimators & Parameters & Estimate of the Parameter & SE & t-ratio & p-value \\
\hline \multirow{9}{*}{ Fixed Effect Model } & $\alpha 1$ & -0.0003 & 0.0001 & -3.4100 & 0.0010 \\
\hline & $\alpha 2$ & 0.0052 & 0.0016 & 3.2000 & 0.0020 \\
\hline & $\alpha 3$ & -0.0084 & 0.0069 & -1.2100 & 0.2280 \\
\hline & $\beta 1$ & 0.1342 & 0.0313 & 4.2900 & 0.0000 \\
\hline & $\beta 2$ & 0.1905 & 0.3946 & 0.4800 & 0.6300 \\
\hline & $\beta 3$ & 0.0000 & 0.0000 & -2.2000 & 0.0300 \\
\hline & $\Upsilon 1$ & 0.0247 & 0.0364 & 0.6800 & 0.4980 \\
\hline & $\Upsilon 2$ & -0.0793 & 0.0766 & -1.0400 & 0.3020 \\
\hline & Constant & 55.9326 & 2.4784 & 22.5700 & 0.0000 \\
\hline Estimators & Parameters & Estimate of the Parameter & SE & t-ratio & p-value \\
\hline \multirow{9}{*}{ Random Effect Model } & $\alpha 1$ & 0.0001 & 0.0001 & 0.8400 & 0.3990 \\
\hline & $\alpha 2$ & 0.0054 & 0.0031 & 1.7500 & 0.0810 \\
\hline & $\alpha 3$ & -0.0101 & 0.0151 & -0.6700 & 0.5040 \\
\hline & $\beta 1$ & 0.1652 & 0.0142 & 11.6400 & 0.0000 \\
\hline & $\beta 2$ & -2.1956 & 0.2612 & -8.4000 & 0.0000 \\
\hline & $\beta 3$ & 0.0000 & 0.0000 & 6.1700 & 0.0000 \\
\hline & $\Upsilon 1$ & 0.0377 & 0.0229 & 1.6500 & 0.0990 \\
\hline & $\Upsilon 2$ & 0.0782 & 0.0959 & 0.8200 & 0.4150 \\
\hline & Constant & 53.3009 & 1.6523 & 32.2600 & 0.0000 \\
\hline Hausman Test & \multicolumn{5}{|c|}{$\operatorname{chi} 2(6)=35.21, p=0.0368$} \\
\hline Comparison One-way vs Two way & \multicolumn{5}{|c|}{$F(16,166)=1.00$, Prob $>F=0.4591$} \\
\hline
\end{tabular}

The coefficient of income per capita and food availability is found to be positive and statistically significant, suggesting that both variables favorably influence health status of the region in periods of good economic growth performance. The results suggest that a $1 \%$ increment on GDP per capita and food availability can generate about 0.007 and 0.03 percentage improvement in health status, respectively. In short, the parameter estimates of the two variables suggest that successful policies that aim at increasing food availability and food entitlement of the citizens of the region can have an impressive impact on the health status of the region. On the other hand, Table 2 reports a negative and statistically significant coefficient of health expenditure. The negative sign might have arisen either from multicollinearity between the income and expenditure per capita, or from the actual impact of the expenditures on health, or from an analytic problem, or from the actual nature of the relationship existing between health expenditures per capita and life expectancy. The latter could happen if society is close to sub-sistence, i.e. has meager, or no savings, and if the expenditures are financed through user fees or taxes collected from the users. In this case, an increase in the expenditures will have a consumption reducing effect of life nurturing and sustaining goods such as food, clothing, housing etc., as it competes for the budget allocated for such types of goods. If the marginal effect of the latter types of goods exceeds that of the former types, the health facilities to be provided by increased expenditures, then it is not surprising to get a negative coefficient for the health expenditures variable. To explore whether the negative coefficient arose from multicollinearity, or from this type of actual relationship, we dropped the GDP per capita and re-estimated the regression. The result is given in Tables 3 and 4. The sign of the coefficient has been changed (- 0.0077 to 0.004 ) which indicates that an increase in health expenditures can have an impact on the improvement of the health status of the region. 
Table 3: One-way error component regression model (without GDP).

\begin{tabular}{|c|c|c|c|c|c|}
\hline Estimators & Parameters & Estimate of the Parameter & SE & t-ratio & p-value \\
\hline \multirow{8}{*}{ Restricted OLS } & $\alpha 2$ & 0.0088 & 0.0013 & 6.6300 & 0.0000 \\
\hline & $\alpha 3$ & 0.0205 & 0.0097 & 2.1100 & 0.0360 \\
\hline & $\beta 1$ & 0.1505 & 0.0139 & 10.7900 & 0.0000 \\
\hline & $\beta 2$ & 1.9227 & 0.2484 & 7.7400 & 0.0000 \\
\hline & $\beta 3$ & -0.0000 & 0.0000 & -6.4200 & 0.0000 \\
\hline & $\Upsilon 1$ & 0.0390 & 0.0213 & 1.8300 & 0.0690 \\
\hline & $\Upsilon 2$ & 0.0757 & 0.0969 & 0.7800 & 0.4350 \\
\hline & Constant & 52.4736 & 1.4176 & 37.0200 & 0.0000 \\
\hline Estimators & Parameters & Estimate of the Parameter & SE & t-ratio & p-value \\
\hline \multirow{8}{*}{ Fixed Effect Model } & $\alpha 2$ & 0.0040 & 0.0008 & 5.1200 & 0.0000 \\
\hline & $\alpha 3$ & 0.0322 & 0.0058 & 5.5300 & 0.0000 \\
\hline & $\beta 1$ & 0.1703 & 0.0386 & 4.4100 & 0.0000 \\
\hline & $\beta 2$ & 0.2037 & 0.4782 & 0.4300 & 0.6710 \\
\hline & $\beta 3$ & -0.0000 & 0.0000 & -1.7500 & 0.0820 \\
\hline & $\Upsilon 1$ & 0.2255 & 0.0380 & 5.9300 & 0.0000 \\
\hline & $\Upsilon 2$ & -0.1537 & 0.0924 & -1.6600 & 0.0980 \\
\hline & Constant & 42.6180 & 2.6465 & 16.1000 & 0.0000 \\
\hline Estimators & Parameters & Estimate of the Parameter & SE & t-ratio & p-value \\
\hline \multirow{8}{*}{ Random Effect Model } & $\alpha 2$ & 0.0047 & 0.0008 & 5.9600 & 0.0000 \\
\hline & $\alpha 3$ & 0.0348 & 0.0056 & 6.2100 & 0.0000 \\
\hline & $\beta 1$ & 0.1329 & 0.0273 & 4.8700 & 0.0000 \\
\hline & $\beta 2$ & -0.4495 & 0.4207 & -1.0700 & 0.2850 \\
\hline & $\beta 3$ & -0.0000 & 0.0000 & -1.3300 & 0.1840 \\
\hline & $\Upsilon 1$ & 0.1567 & 0.0291 & 5.3800 & 0.0000 \\
\hline & $\Upsilon 2$ & -0.1807 & 0.0913 & -1.9800 & 0.0480 \\
\hline & Constant & 47.1183 & 1.9210 & 24.5300 & 0.0000 \\
\hline Hausman Test & \multicolumn{5}{|c|}{$\operatorname{chi} 2(6)=27.61, p=0.0001$} \\
\hline
\end{tabular}

Table 4: Two-way error component regression model (without GDP).

\begin{tabular}{|c|c|c|c|c|c|}
\hline Estimators & Parameters & Estimate of the Parameter & SE & t-ratio & p-value \\
\hline \multirow{8}{*}{ Fixed Effect Model } & $\alpha 2$ & 0.0004 & 0.0008 & 0.51 & 0.614 \\
\hline & $\alpha 3$ & -0.0119 & 0.0069 & -1.74 & 0.085 \\
\hline & $\beta 1$ & 0.1295 & 0.0318 & 4.07 & 0 \\
\hline & $\beta 2$ & 0.2647 & 0.3995 & 0.66 & 0.509 \\
\hline & $\beta 3$ & 0 & 0 & -2.03 & 0.044 \\
\hline & $\Upsilon 1$ & 0.0288 & 0.0372 & 0.77 & 0.441 \\
\hline & $\Upsilon 2$ & -0.047 & 0.0768 & -0.61 & 0.541 \\
\hline & Constant & 55.6219 & 2.5052 & 22.2 & 0 \\
\hline Estimators & Parameters & Estimate of the Parameter & SE & t-ratio & p-value \\
\hline \multirow{8}{*}{ Random Effect Model } & $\alpha 2$ & 0.0009 & 0.0007 & 1.19 & 0.234 \\
\hline & $\alpha 3$ & -0.0111 & 0.0066 & -1.69 & 0.091 \\
\hline & $\beta 1$ & 0.1179 & 0.0271 & 4.35 & 0 \\
\hline & $\beta 2$ & 0.0351 & 0.373 & 0.09 & 0.925 \\
\hline & $\beta 3$ & 0 & 0 & -0.78 & 0.436 \\
\hline & $\Upsilon 1$ & 0.0402 & 0.0312 & 1.29 & 0.197 \\
\hline & $\Upsilon 2$ & -0.0463 & 0.0742 & -0.62 & 0.533 \\
\hline & Constant & 54.7188 & 2.2651 & 24.16 & 0 \\
\hline Hausman Test & \multicolumn{5}{|c|}{$\operatorname{chi} 2(6)=8.68, p=0.9948$} \\
\hline Comparison One-way vs Two way & \multicolumn{5}{|c|}{$F(16,173)=0.90$, Prob $>F=0.5713$} \\
\hline
\end{tabular}


Moreover, Table 2 reports that the coefficient of the literacy ratio has a statistically strong impact on health status, $(\mathrm{P}=0.000)$, suggesting that a $1 \%$ increase in the literacy would lead to $0.17 \%$ increment in life expectancy. As previously discussed, this is possible as more education gives the people more awareness about their own health status and of what preventive measures would increase their own health. Furthermore, the table indicates that an increase in urbanization rate, decrease in alcohol consumption, decrease in carbon dioxide emission, and decrease in population growth rate may contribute to the improvement of health status. This suggestion is, however, not supported by statistical test of significance. According to Grossman (1972), this may improve or depreciate depending upon the socioeconomic and environmental factors that act as input to the production function. In general, the estimates suggest that an increase in food availability and income per capita can contribute to life expectancy. Hence, it is possible to assert cautiously that the two economic variables play a substantial role in the improvement of the health status of the region. Health service variables, i.e., physician and population per thousand people is not statistically significant. Environmental conditions are important determinants of health status. The effect of carbon dioxide emission is negative while effect of urbanization is positive. So, there is also some indication of harmful effects from carbon dioxide emission.

\section{Discussion}

The study has estimated a health production function for Asian developing countries in line with Grossman theoretical model using socioeconomic and environmental factors as inputs of the production system. The main data source for study is the World Bank data set. The results obtained from two-way random effect regression model suggest that an increase in GDP per capita, literacy rate, and food availability have a significant favorable effect on life expectancy. Health expenditure has shown a strong negative relationship with life expectancy, which possibly arises from inefficient health service provision systems. Moreover, an increase in urbanization, a decrease in the population growth rate, a decrease in adult alcohol per capita consumption growth rate, a decrease in Carbon dioxide emissions per capita growth rate are found to improve life expectancy, though this argument cannot be supported based on the statistical significance of the tests. In general, the results suggest that a health policy which may focus on the provision of health services, family planning programs, and emergency aids and ignores the marginal efficiencies of the services, and other socio-economic aspects may do little in efforts directed to improve the existing health status of the region. Lastly, from the estimated health production function and the region's past socioeconomic performances, we observe the fact that making substantial improvements of the health status of Asian developing countries are within the realm of possibility.

\section{Conclusion}

The main conclusion of this study is that GDP per capita, food availability and literacy rate variables positively effect on health status and their roles are becoming important over time. These variables have remained important for all countries irrespective of their developmental stage. Urbanization can be used as an important variable to improve health status, but its effectiveness may be limited. Similarly, carbon dioxide emission has negative impact on health status. However, these results should be interpreted with care as the aggregation may have concealed important policy information. Therefore, it may be important to do the same analysis for individual countries.

\section{References}

1. Grossman M (1972) The Demand for Health: A Theoretical and Empirical Investigation. NBER 135.

2. Correa H, K Namkoong (1992) Determinants and Effects of Health Policy. Journal of Policy Modelling 14(1): 41-63.

3. Folop T, O W A Rinke (1983) Health Manpower in Relation to Socioeconomic Development and Health Status. In: Salkencr Sirageldin and Sorkin (Eds.), Research in Human Capital and Development JAI Press Inc.

4. Gerdtham Ulf G, B Jonsson (1992) International Comparisons of Health Care Expenditure-Conversion Factor Instability, Heteroscedasticity, Outliers and Robust Estimators. Journal of Health Economics 11(2): 189-197.

5. Grosse RN, BH Perry (1983) Correlates of Life Expectancy in Less Developed Countries. Health Policy and Education 2(3-4): 274-304.

6. Hitiris T, J Posnett (1992) The Determinants and Effects of Health Expenditure in Developed Countries. Journal of Health Economics 11(2): 173-181.

7. Wheeler D (1980) Basic Needs Fulfilment and Economic Growth: A Simultaneous Model, Journal of Development Economics 7(4): 435-451.

8. Grosse RN, BH Perry (1983) Correlates of Life Expectancy in Less Developed Countries. Health Policy and Education 2(3-4): 275-304.

9. Marmot M, R Wilkinson (2006) Social Determinants of Health. Oxford University Press.

10. Bloom D, Canning D (2003) The health and poverty of nations: from theory to practice. Journal of Human Development 4(1): 47-71. 
ISSN: 2574-1241

DOI: 10.26717/BJSTR.2020.24.004018

SM Zahedul Islam Chowdhury. Biomed J Sci \& Tech Res

(c) (P) This work is licensed under Creative

Submission Link: https://biomedres.us/submit-manuscript.php

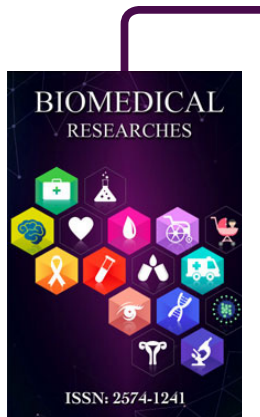

Assets of Publishing with us

- Global archiving of articles

- Immediate, unrestricted online access

- Rigorous Peer Review Process

- Authors Retain Copyrights

- Unique DOI for all articles 